\title{
Social Network Evolution: The Case of UK Companies Before and After Brexit
}

\author{
Edward Edward ${ }^{1 *}$, Amjad Fayoumi ${ }^{2}$, Azar Shahgholian ${ }^{3}$, Achmad Hidayanto ${ }^{1}$ \\ ${ }^{1}$ University of Indonesia, U.I. Campus, Depok-16424, Indonesia. \\ ${ }^{2}$ Lancaster University, Lancaster - LA1 4YW, United Kingdom. \\ ${ }^{3}$ Liverpool John Moores University, Tithebarn St, Liverpool - L2 2QP, United Kingdom.
}

\begin{abstract}
The Brexit referendum has impacted both the UK and the EU economies in several ways. The uncertainty around Brexit highlighted the importance of a relationships network between directors of companies to access information and resources that are necessary for optimal decision making. It is difficult to develop informed business and economy policies without a deep understanding of the magnitude of Brexit on business-to-business relationships with EU-based firms. This study aims to analyze the impact of the passage of the Brexit referendum on the evolution of board interlock networks. The study uses network analysis to measure the evolution of UK-EU directors' relationships over the Brexit period, predominantly between the 2010 and 2020 period. The study models the structural changes in dynamic networks by converting this evolving network into static graphs on yearly basis. The analysis indicates that links formation in the UK is affected negatively by the Brexit referendum. It also has a negative impact on forming a new link with potential companies' directors in the EU, but it shows a rising tendency for shared affiliation bias analysis. Interestingly, the contradicted trend in 2007 , the number of directors' connection in consumer service and food \& drug sectors was decreasing in the UK while rocketing in the EU.
\end{abstract}

\section{Keywords:}

Brexit;

Companies Relationship Network;

Social Network Evolution;

Dynamic Social Network.

\section{Article History:}

Received: 24 June 2021

Revised: $\quad 06 \quad$ November 2021

Accepted: $\quad 09$ December 2021

Published: 01 February 2022

\section{1- Introduction}

The Brexit referendum in 2016 with $51.9 \%$ of voters agreed to leave the European Union (EU) has affected economy sector. It might limit the movement of capital, because being the member of EU will make it easier for the investor to invest from other EU countries to UK [1]. Next, leaving the EU Single Market might result the UK export platform becoming less attractive and could not take advantage of the borderless trade with other members of EU [1,2]. And the last, for multinationals companies, it might cause a problem since they have complex supply chain systems and extensive co-ordination processes between the head office and their subsidiary [2]. It is proven that a diverse set of interpersonal relationships with suppliers positively impacts supply-side resilience [3]. In addition, the perseverance of corporates elites is formed by the connection of the directors $[4,5]$. The companies tend to occupy the board position from their coalition partners [6]. These connections are shaped to spread the latest and important information and also the best managerial policy [7-10].

In a globalized world, social networks take an inseparable role in everyday professional life. Nowadays, professionals experience a situation where tremendous amount of data are made available for analysis and support decision making due to the fast development of information and communication technologies. Nevertheless, not every question can be

*CONTACT: edward81@ui.ac.id

DOI: http://dx.doi.org/10.28991/ESJ-2022-06-01-01

(C) 2022 by the authors. Licensee ESJ, Italy. This is an open access article under the terms and conditions of the Creative Commons Attribution (CC-BY) license (https://creativecommons.org/licenses/by/4.0/). 
easily answered by skimming through the data, simply because it needs to be systematically analyzed and visualized to create an informative model. Withers et al. (2018) and Lang \& Lockhart (1990) [6, 11] proved that social network could be used to find the impact of environmental changes on the evolution of the board interlock network.

Many researchers give their attention to statistical perspective while ignoring the social network's dynamic and time constraints $[12,13]$. Although dynamic network research is not as popular as static network study, network dynamic could capture missing elements which static networks could not provide [14]. The concept of network evolution and the way networks form have been gaining considerable attention in academia mostly due to its pertinence to the development of various popular research such as big data processing [29], information diffusion in social networks [30], distributed search [31], evolution pattern mining on dynamic social network [32] and knowledge exchange and innovation through dynamic social network lens [33]. Examining dynamic social networks overcomes the static network problems. Firstly, dynamic network will provide more accurate information compared to a static network. Secondly, static network could not reveal the pattern of change in the network while dynamic network could. Thirdly, dynamic networks are crucial if the network relationship between transmission probability and edge weight is non-linear. Lastly, dynamic social is effective in dense network interaction between the nodes.

In this paper, the researchers analyzed the effect of UK Brexit to the evolution of connection between directors in UK and EU, discovered the sector most affected and having a significant impact after Brexit. The probability of making a relation between the directors in the future is increasing in accordance with the number of mutual friends that can be applied by cyclic closure bias and triadic closure bias [15]. This study concentrates on the evolve of the social network $[15,16]$ and the impact of Brexit [17-19]. It will contribute to board interlock networks $[6,15,16,20,21]$ and explain the evolution of directors establishing a new connection and removing a connection to face the UK Brexit. The inspiration to pursue this study stems directly from the precursor to this study conducted by Shahgholian, et al. (2012) where the authors examined the evolution of UK directors' social network. They found that directors who are not connected directly in specific year and have only a single intermediary between them are more likely to form a connection in the future than the directors with two intermediaries [15]. Today, we are in the post-Brexit stage and companies have already experienced the uncertainty through various stages of the Brexit. Directors and companies were really more than before on their social network links to access to other companies' experiences and timely information which are critical for decision making. This research aims to explore whether Brexit referendum has impacted the relationship between directors in the UK and their counterparts in the EU. We are specially examine to what extent business relations were impacted and which sectors are most affected. The rest of this paper is organized as follows. Section (2) Related Works: summarizes the related work on the previous literature. Section (3) Research Methodology: illustrates the research methodology, including dataset and measurement, and the research flow. Section (4) Results and Analysis: explains the results of this study. Section (5) Conclusions: concludes the paper.

\section{2- Related Works}

In corporate governance, board capital consists of human capital and social capital. Human capital is a set of skills and knowledge developed through education, training and political experience [22, 23]. Professionals' experiences also form human capital in the business environment. Social capital of the board is creating through appointing outside directors, which creates board interlocks where a tie between two boards are established. In another study, Coleman (1988) in his book explained the process of social capital [24]. He stated that an essential form of social capital is the information that exists on social relations. This can be used for other purposes, such as for obtaining information at minimum cost. Board social capital can provide new resources, exchange information, and build connections with other firms [25]. Outside directors build their social capital to obtain external resources and leverage their experience and skills [26]. Recently, the role of board interlocks are examined in relation various aspects of their companies such as firm performance [34], GHG emission [35] and utilizing new technologies [36]. Mizruchi (1996) argued that interlocking directors is a way to diffuse their influence, increase their centrality and other variety of reasons (i.e. collusion, legitimacy, social cohesion, etc.) [27]. There have been multiple comparative studies that analysed evolving director networks in the following directions: before and after a crucial decision has been made [37], and the effect of board interlocks on short-term and long-term market behaviour [38]. Kurt \& Kurt (2020) also highlighted the role of companies' social network in international business [39].

Several studies have examined how a major environmental change contributes significantly in forming the board interlocking network. Lang and Lockhart (1990) found that deregulation of the airline industry creating uncertainty positively impacts directors interlocking among the rivalry [11]. Another study conducted by Withers and Howard (2018), involving 220 companies examined the effect of Sarbanes-Oxley (SOX) legislation of 2002 on the market for the boards as well as the evolution of the board interlock network [6]. The study found that the change of regulation affects the social relation between the directors. More recent research from Shahgholian, et al. (2012) studied the evolution of UK directors in a period of twelve years using the dataset from BoardEx [15]. The study calculates two measures, namely shortest path length and number of shared affiliations, in different year snapshots. They confirmed the result from an earlier study conducted by Kossinets \& Watts (2006) argued that the number of mutual friends and the strong tie with those friends leads to the creation of links in companies [16]. 


\section{3- Research Methodology}

\section{3-1-Dataset}

The research focuses on the periods around pre, during and post Brexit referendum and execution. The time line of Brexit is shown in Figure 1.

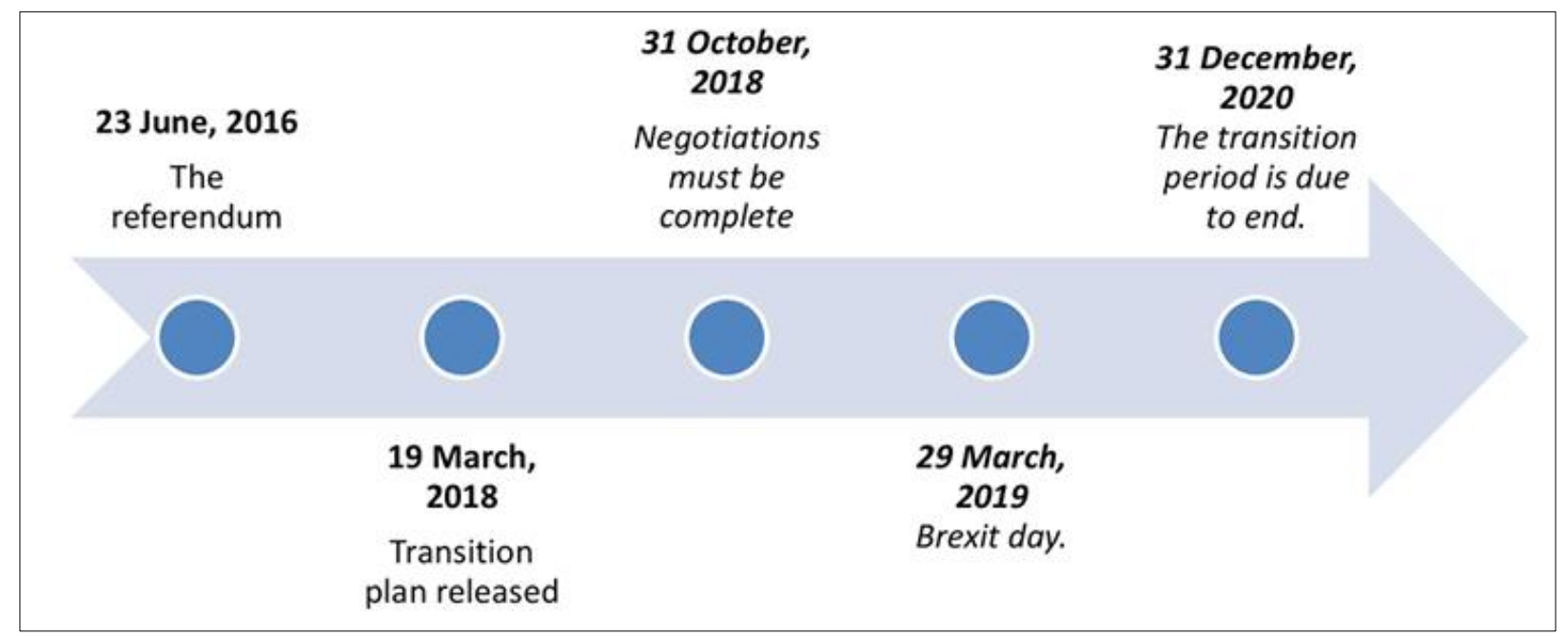

Figure 1. Brexit Timeline

This study used a quantitative approach with a survey research strategy based on secondary data. The data is collected from BoardEX, a comprehensive database containing profiles for more than one million managers and directors worldwide. The data source contains two sets of data. The first one includes the directors' profile in United Kingdom companies, and the other one gives information about the boards in European Union companies. The research focuses on the data between 2010 and 2020 to find the effect before and after Brexit. Figure 2 presents the research methodology steps.

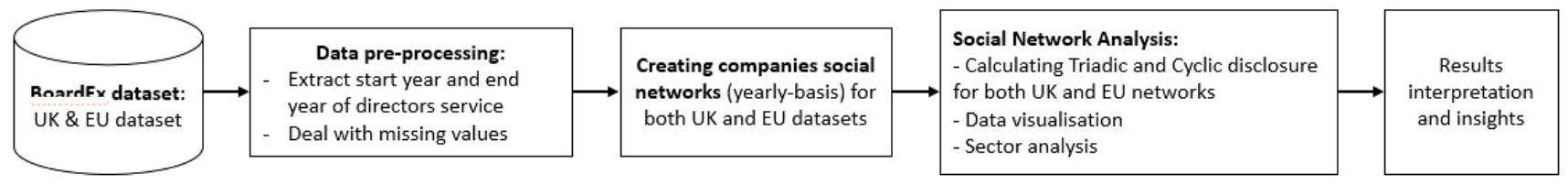

Figure 2. Research Methodology Steps

\section{3-2-Structure}

This study is carried out to determine the social network of board directors. The data can be grouped by the "DateStartRole" and "DateEndRole" in a 11-year range, from 2010-2020 to analyze the evolution of the network. The data is classified in PostgreSQL, and the result is exported to each year table. To create the bond among the directors, the term "Current Employment Network" defined by Shahgholian, et al. (2012) [15] is followed. Next, creating the list of directors or the nodes which involved in the network to develop the network system by filtering the "BrdPosition" and creating a connection between the board with the same "Companyld" field each year to decide the director which was working in the same organization.

Analysis in this study mainly builds upon scrutinizing the formation of new links between a set of directors in UK and EU over the years. The first step is transforming the structure of the network into a static graph at different yearly basis snapshots of network from 2010 to 2020. Furthermore, the pattern of evolution between two consecutive year needs to find and then compare the generated snapshots in the UK and EU. Details of the three sets of network measures that will be quantified are as follows.

\section{Cyclic Closure Bias}

This measure is used to find the actual probability of a pair of directors who previously did not know and at X distance apart will form a new connection in the future. The example is shown in Figure 1. 


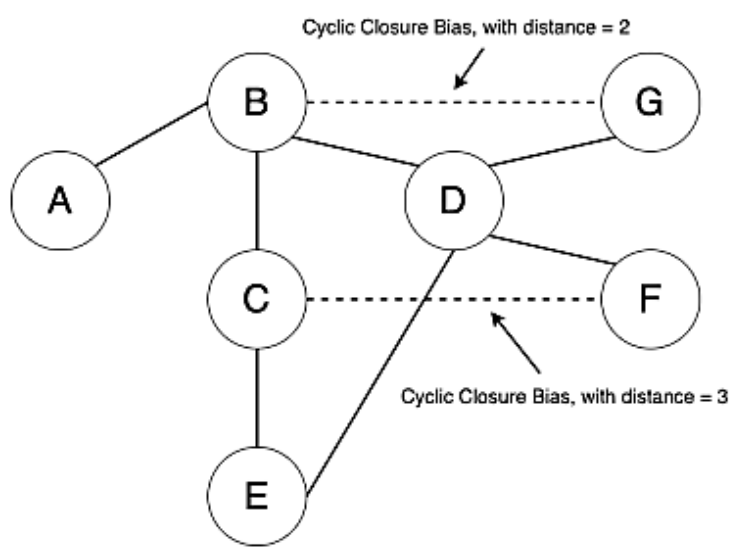

Figure 3. Cyclic Closure Bias

The distances of two and three are used for unacquainted directors to determine any pattern of closure based on distances and applied in "Current Employment Network" to find out the current trend between the UK and EU from 2010 to 2020. The number of pairs of directors with the distance two and three is calculated using the NetworkX library in Python. Firstly, the network is built by adding the nodes and edges for each year into the graph where nodes are companies and edges are interlock links between them. Next, an iteration process for each node is paired with other nodes to get the shortest path of them using the "all_pairs_shortest_path_length" function and stored it into a csv file. The csv file is imported to PostgresSQL and runs a query to find the pair of nodesthat have a distance of two and three in the network.

\section{Triadic Closure Bias}

This measure used to the actual probability of a pair of directors who are previously not acquainted will form a new connection in the future based on their shared affiliations. The example is shown in Figure 2.

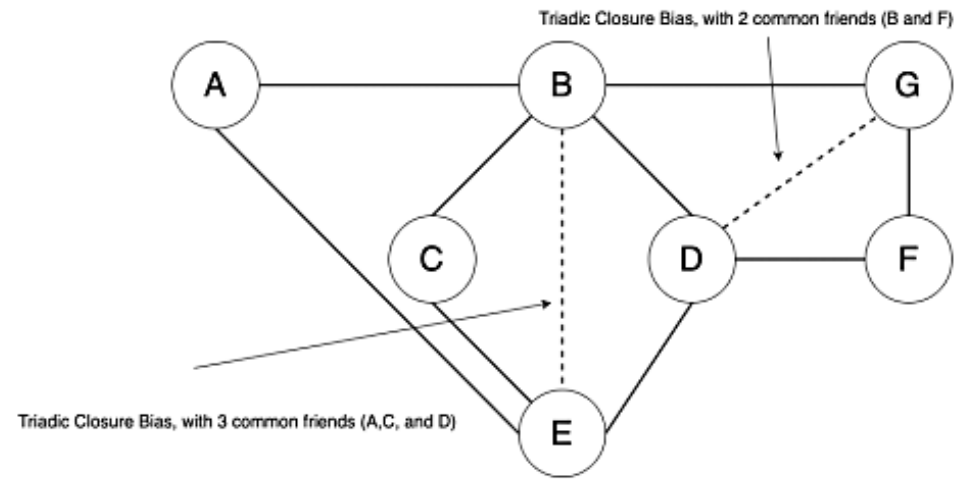

Figure 4. Triadic Closure Bias

This measure uses $1,2,3,4$, and $>=5$ mutual friends to disclose the empirical probability of triadic closure for the pair of directors. The result of various number of shared connections will be utilized to determine the effect of number of connection on forming a new connection of two directors at some point in the future which previously were disconnected. The number of mutual friends between the directors with 5 categories (1-5 shared friends) are calculated using NetworkX library in Python. Firstly, the networks are built by adding the nodes and edges for each year into the graph. Next, an iteration process for each node is paired with other nodes to check their same friends using "common_neighbors" function and stored in a csv file. The csv file is imported to PostgresSQL and runs a query to find the pair of nodes that have shared connections of $1,2,3,4,>=5$ in the network.

\section{Number of Edges}

The number of edges is compared within the "sector" field to know the sector most affected by Brexit in UK, and EU. However, in this BoardEX dataset, not all the rows in the "sector" field has a value. Some of them are "NULL". Hence, the "Current Employment Network" term is still used, but "sector" field filtering is added for this case. Firstly, the "BrdPosition" field that contains "Yes" and "Inside" values are filtered to get the boards that have an active role such as "Trustee", "Chairman", or "Advisor" and create a connection between the board with the same "Companyld" field each year. Next, another filter that only gets the row with "NOT NULL" value is added to determine the director 
working in the same organization and sector. Furthermore, the queries are created to generate the edges with the sectors and imported into PostgresSQL.

\section{4- Results and Discussion}

\section{4-1-Network Point of View Using Cyclic Closure Bias}

The following part depicts the results and analysis of cyclic closure for the Current Employment Network of boards for two regions with two different shortest path distances over the period of eleven years.

\section{Result}

The network evaluation of cyclic closure bias for the Current Employment Network over a ten years of the UK region presented in Table 1 and Table 2 depicts the network evolution for the EU region. For each row in every table, Yi in the first column denotes the year in which the boards with the shortest path distance of length 2 and 3 is evaluated in the network. Yi+1 in the second column represents the new links formed between the boards in the next year, which will be evaluated.

\section{Analysis}

From Table 1 and Table 2, it can be clearly seen that the probability of the directors separated with two mediators (Dd1-d2 = 3) is 5 to 9 times for the UK region and 8 to 12 times for the EU region less than those with one mediator (Dd1-d2 = 2). It confirms the statement stated in the previous literature. Shahgholian, et al. (2012) and Kossinets \& Watts (2006) argued that the directors separated with a single intermediary is more likely to create a new connection at some point in the future compared to the directors with two mediators $[15,16]$.

Table 1. Cyclic Closure Bias Evaluation in UK

\begin{tabular}{|c|c|c|c|c|c|c|c|c|}
\hline \multirow[b]{2}{*}{$\mathbf{Y}_{\mathbf{i}}$} & \multirow[b]{2}{*}{$\mathbf{Y}_{\mathrm{i}+1}$} & \multicolumn{3}{|c|}{$D_{\mathrm{d} 1-\mathrm{d} 2}=2$} & \multicolumn{3}{|c|}{$D_{\mathrm{d} 1-\mathrm{d} 2}=3$} & \multirow[b]{2}{*}{$\begin{array}{c}\Delta \mathrm{F}= \\
\mathrm{F} 2 / \mathrm{F3}\end{array}$} \\
\hline & & $\begin{array}{c}\text { Possible Pairs } \\
\text { in }\left(Y_{i}, \mathbf{P} 2\right)\end{array}$ & $\begin{array}{l}\text { Pairs Connected } \\
\text { in }\left(Y_{i+1}, C 2\right)\end{array}$ & $\begin{array}{l}\text { Fraction Pairs } \\
\text { Connected F2 } \\
=\mathrm{C} 2 / \mathrm{P} 2\end{array}$ & $\begin{array}{l}\text { Possible Pairs } \\
\text { in }\left(\mathbf{Y}_{\mathrm{i}}, \mathbf{P 3}\right)\end{array}$ & $\begin{array}{c}\text { Pairs Connected } \\
\text { in }\left(\mathbf{Y}_{\mathrm{i}+1}, \mathrm{C} 3\right)\end{array}$ & $\begin{array}{c}\text { Fraction Pairs } \\
\text { connected } \\
\mathrm{F3}=\mathrm{C} 3 / \mathrm{P3}\end{array}$ & \\
\hline 2010 & 2011 & 430.513 & 541 & 0.0012566 & 2.474 .349 & 617 & 0.0002494 & 5.04 \\
\hline 2011 & 2012 & 441.516 & 672 & 0.001522 & 2.563 .832 & 593 & 0.0002313 & 6.58 \\
\hline 2012 & 2013 & 477.756 & 749 & 0.0015677 & 2.807 .450 & 614 & 0.0002187 & 7.17 \\
\hline 2013 & 2014 & 502.893 & 774 & 0.0015391 & 2.978 .066 & 748 & 0.0002512 & 6.13 \\
\hline 2014 & 2015 & 558.503 & 908 & 0.0016258 & 3.455 .385 & 894 & 0.0002587 & 6.28 \\
\hline 2015 & 2016 & 606.750 & 1325 & 0.0021838 & 3.771 .168 & 887 & 0.0002352 & 9.28 \\
\hline 2016 & 2017 & 633.374 & 1106 & 0.0017462 & 3.808 .790 & 1012 & 0.0002657 & 6.57 \\
\hline 2017 & 2018 & 634.499 & 1112 & 0.0017526 & 3.834 .891 & 1081 & 0.0002819 & 6.22 \\
\hline 2018 & 2019 & 638.340 & 1025 & 0.0016057 & 3.838 .075 & 900 & 0.0002345 & 6.85 \\
\hline 2019 & 2020 & 618.853 & 521 & 0.0008419 & 3.608 .086 & 355 & 0.0000984 & 8.56 \\
\hline
\end{tabular}

Table 2. Cyclic Closure Bias Evaluation in EU

\begin{tabular}{|c|c|c|c|c|c|c|c|c|}
\hline \multirow[b]{2}{*}{$\mathbf{Y}_{\mathbf{i}}$} & \multirow[b]{2}{*}{$\mathbf{Y}_{\mathbf{i}+1}$} & \multicolumn{3}{|c|}{$D_{\mathrm{d} 1-\mathrm{d} 2}=2$} & \multicolumn{3}{|c|}{$D_{\mathrm{d} 1-\mathrm{d} 2}=3$} & \multirow[b]{2}{*}{$\begin{array}{c}\Delta \mathrm{F}= \\
\mathrm{F} 2 / \mathrm{F3}\end{array}$} \\
\hline & & $\begin{array}{l}\text { Possible Pairs } \\
\text { in }\left(Y_{i}, \mathbf{P 2}\right)\end{array}$ & $\begin{array}{l}\text { Pairs Connected } \\
\text { in }\left(\mathbf{Y}_{\mathrm{i}+1}, \mathrm{C} 2\right)\end{array}$ & $\begin{array}{c}\text { Fraction Pairs } \\
\text { Connected F2 } \\
=\mathrm{C} 2 / \mathrm{P} 2\end{array}$ & $\begin{array}{l}\text { Possible Pairs } \\
\text { in }\left(\mathbf{Y}_{\mathbf{i}}, \mathbf{P 3}\right)\end{array}$ & $\begin{array}{l}\text { Pairs Connected } \\
\text { in }\left(\mathbf{Y}_{i+1}, \mathbf{C} 3\right)\end{array}$ & $\begin{array}{c}\text { Fraction Pairs } \\
\text { connected } \\
\text { F3 = C3/P3 }\end{array}$ & \\
\hline 2010 & 2011 & 1.809 .281 & 3709 & 0.00205 & 13.207 .229 & 2363 & 0.0001789 & 11.46 \\
\hline 2011 & 2012 & 1.945 .776 & 4295 & 0.0022073 & 14.498 .705 & 2898 & 0.0001999 & 11.04 \\
\hline 2012 & 2013 & 2.056 .446 & 4705 & 0.0022879 & 15.374 .492 & 2821 & 0.0001835 & 12.47 \\
\hline 2013 & 2014 & 2.052 .890 & 4340 & 0.0021141 & 15.257 .973 & 2799 & 0.0001834 & 11.52 \\
\hline 2014 & 2015 & 2.039 .499 & 4850 & 0.002378 & 15.232 .368 & 2855 & 0.0001874 & 12.69 \\
\hline 2015 & 2016 & 2.057 .903 & 4631 & 0.0022503 & 15.245 .845 & 3081 & 0.0002021 & 11.14 \\
\hline 2016 & 2017 & 2.123 .494 & 4530 & 0.0021333 & 15.749 .038 & 2783 & 0.0001767 & 12.07 \\
\hline 2017 & 2018 & 2.110 .340 & 4312 & 0.0020433 & 15.236 .984 & 2990 & 0.0001962 & 10.41 \\
\hline 2018 & 2019 & 2.146 .928 & 3531 & 0.0016447 & 15.392 .923 & 2425 & 0.0001575 & 10.44 \\
\hline 2019 & 2020 & 1.962 .868 & 889 & 0.0004529 & 13.633 .095 & 731 & 0.0000536 & 8.45 \\
\hline
\end{tabular}


The total number of director pairs with the shortest path distance of lengths 2 and 3 are represented by P2 and P3, respectively. The total number of director pairs of lengths 2 and 3 that created a new pair in year Yi+1 are represented by $\mathrm{C} 2$ and C3, respectively. F2 and F3 represent the fraction or the empirical probability of the boards which connected each year with the shortest path distance of lengths 2 and 3 accordingly. The likeliness of F2 over F3 is represented by $\Delta \mathrm{F}$.

Figure 3 shows the comparison of empirical probability forming a new link between the directors in the UK and EU with the shortest path distance of lengths 2 and 3 over a ten years. As it can be observed from Figure 3, there is an upward trend of the probability of creating a new connection from 2011 to 2016 for a distance of 2 for the UK region. The empirical probability is counted for 0.0012566 in 2011 and climb to 0.0016258 in 2015 . Next, there is a significant surge, with almost 35 percent in 2016. At this point, the trend reversed. It starts to decrease remarkably from 0.0021838 in 2016 to 0.0017462 or decline about 20 percent in 2017 and starts to fall over the year.

Overall the probability of creating a new connection in the EU with 1 intermediary is fluctuated throughout the year from 2011 to 2015 and reach 0.0023780 in the same year. However, it has a downward trend after 2015. As it can be observed from the Figure 4, there is a fluctuated trend of probability of creating a new connection from 2011 to 2018 for distance of 3 for the UK and EU region. The empirical probability is counted for 0.0002494 for the UK region and 0.0001789 for the EU region in 2011. For the UK region, the probability reaches the lowest point with 0.0002187 in 2013 and reach the peak 2018 counted for 0.0002819 . After 2018 , the probability declines sharply over the years. While in the EU region, it hit a high-point in 2016 with 0.0002021 and similar to the UK region, it has started to fall after 2018.

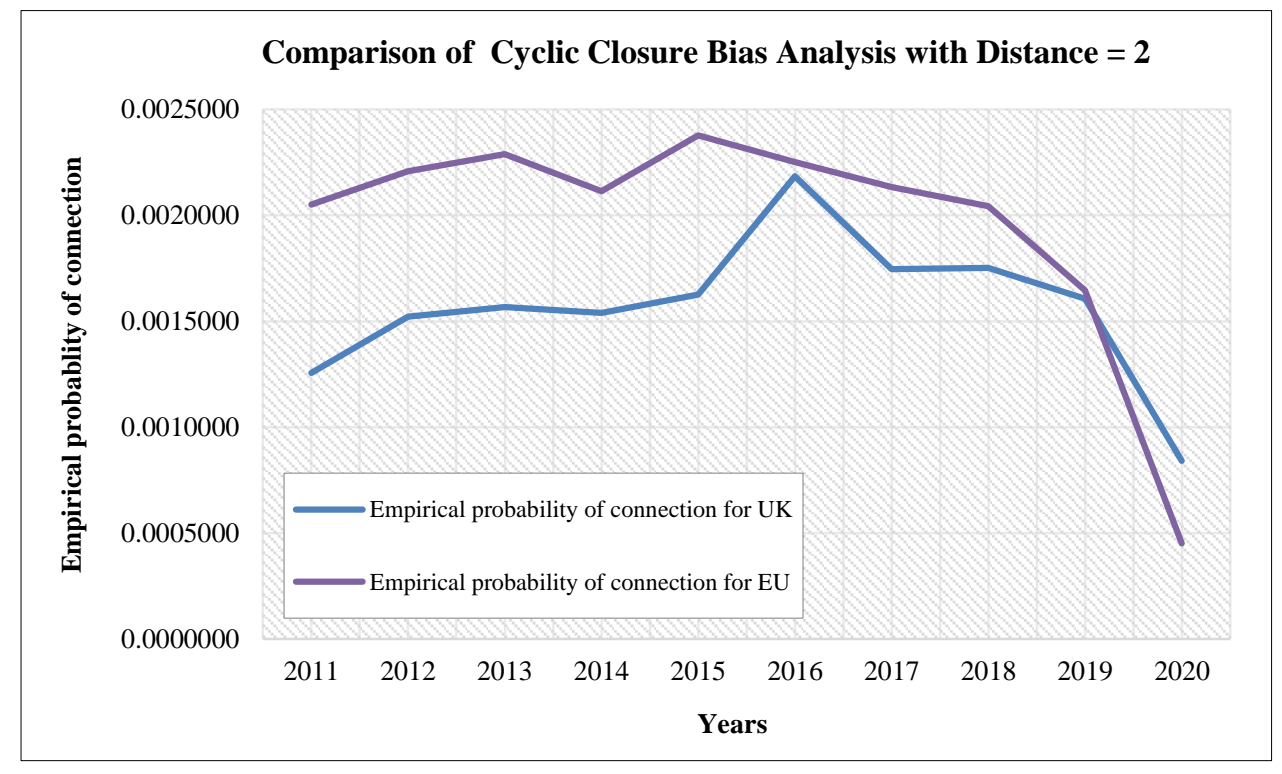

(a)

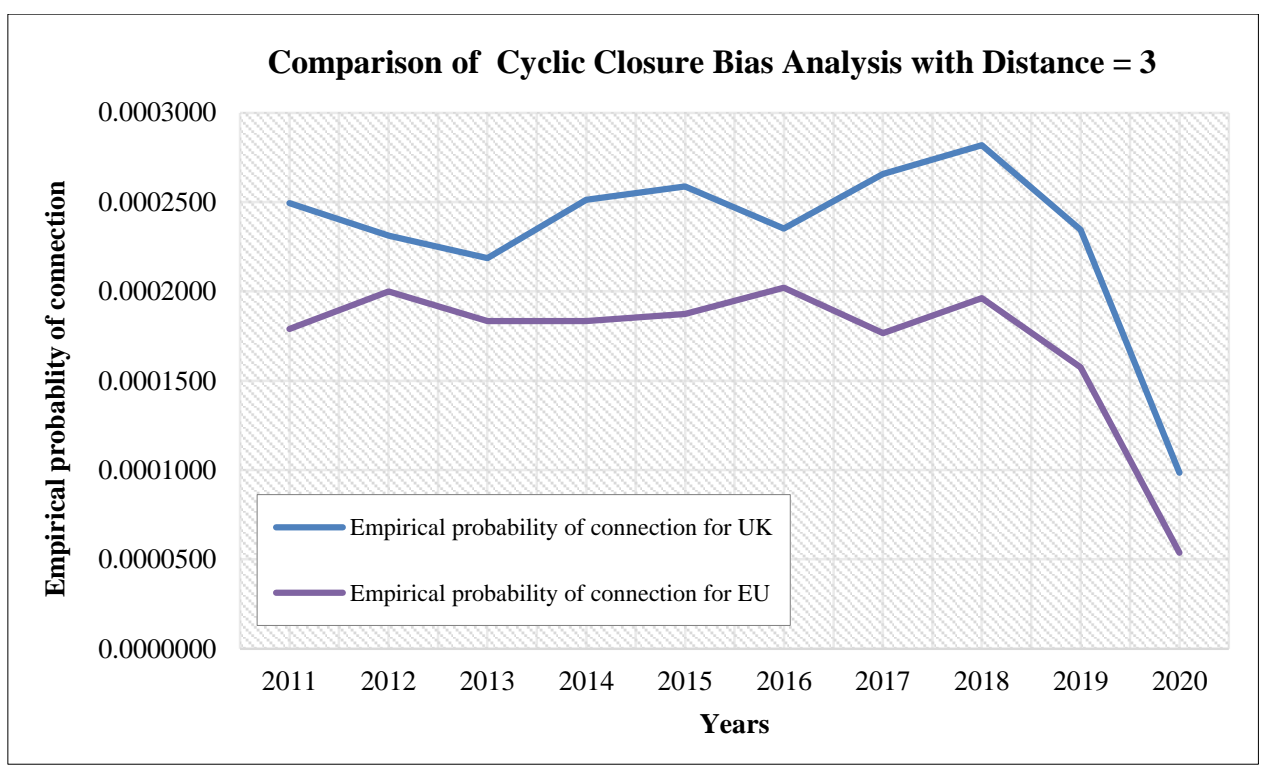

(b)

Figure 5. Comparison Analysis for Cyclic Closure Bias: (a) Cyclic Closure Bias with Distance = 2; (b) Cyclic Closure Bias with Distance $=3$ 


\section{4-2-Network Point of View using Shared Affiliation Bias}

The following part depicts the results and analysis of shared affiliation bias for the Current Employment Network of boards for two regions with five different categories of mutual friends over the period of eleven years.

\section{Result}

The network evaluation of shared affiliation bias for the Current Employment Network over a 10 year of the UK region is presented in Tables 3 and 4 depicts the network evolution for EU region. For each row in every table, Yi in the first column denotes the year in which the boards with mutual friends of $1,2,3,4,>=5$ is evaluated in the network. $\mathrm{Yi}+1$ in the second column represents the new links formed between the boards in the next year, which will be evaluated. F1, F2, F3, F4, and F5 represent the fraction of the empirical probability of the boards which possibly connected in year Yi and actually connected next year with mutual friends of 1, 2, 3, 4, and >=5.

Table 3. Shared Affiliation Bias Evaluation in UK

\begin{tabular}{|c|c|c|c|c|c|c|}
\hline $\mathbf{Y}_{\mathbf{i}}$ & $\mathbf{Y}_{\mathrm{i}+\mathbf{1}}$ & $\begin{array}{c}\text { Fraction Pairs } \\
\text { Connected for Mutual } \\
\text { Friends = } 1 \text { (F1) }\end{array}$ & $\begin{array}{c}\text { Fraction Pairs } \\
\text { Connected for Mutual } \\
\text { Friends }=2(\mathrm{~F} 2)\end{array}$ & $\begin{array}{c}\text { Fraction Pairs } \\
\text { Connected for Mutual } \\
\text { Friends = 3 (F3) }\end{array}$ & $\begin{array}{c}\text { Fraction Pairs } \\
\text { Connected for Mutual } \\
\text { Friends }=4(\mathrm{F4})\end{array}$ & $\begin{array}{c}\text { Fraction Pairs } \\
\text { Connected for Mutual } \\
\text { Friends }>=5(\text { F5) }\end{array}$ \\
\hline 2010 & 2011 & 0.0105798 & 0.1751171 & 0.4122511 & 0.4762096 & 0.4825119 \\
\hline 2011 & 2012 & 0.0108542 & 0.1900783 & 0.4362467 & 0.4674809 & 0.4763202 \\
\hline 2012 & 2013 & 0.0105499 & 0.1702143 & 0.3497335 & 0.4482123 & 0.4655517 \\
\hline 2013 & 2014 & 0.010134 & 0.1610227 & 0.3697479 & 0.4458562 & 0.4563724 \\
\hline 2014 & 2015 & 0.0094752 & 0.1463159 & 0.3618207 & 0.4348103 & 0.4455099 \\
\hline 2015 & 2016 & 0.0095219 & 0.1424592 & 0.3286484 & 0.4091498 & 0.4402701 \\
\hline 2016 & 2017 & 0.0091475 & 0.1309491 & 0.2822286 & 0.3867484 & 0.4263204 \\
\hline 2017 & 2018 & 0.0092217 & 0.1368488 & 0.3476175 & 0.4333189 & 0.4443532 \\
\hline 2018 & 2019 & 0.008813 & 0.1492346 & 0.3086817 & 0.403155 & 0.4578702 \\
\hline 2019 & 2020 & 0.0083158 & 0.139275 & 0.3053207 & 0.4147939 & 0.4608833 \\
\hline
\end{tabular}

Table 4. Shared Affiliation Bias Evaluation in EU

\begin{tabular}{|c|c|c|c|c|c|c|}
\hline $\mathbf{Y}_{\mathbf{i}}$ & $\mathbf{Y}_{\mathbf{i}+1}$ & $\begin{array}{c}\text { Fraction Pairs } \\
\text { Connected for Mutual } \\
\text { Friends = } 1 \text { (F1) }\end{array}$ & $\begin{array}{c}\text { Fraction Pairs } \\
\text { Connected for Mutual } \\
\text { Friends = } 2(\text { F2) } \\
\end{array}$ & $\begin{array}{c}\text { Fraction Pairs } \\
\text { Connected for Mutual } \\
\text { Friends }=\mathbf{3}(\mathrm{F3})\end{array}$ & $\begin{array}{c}\text { Fraction Pairs } \\
\text { Connected for Mutual } \\
\text { Friends }=4(\mathrm{~F} 4)\end{array}$ & $\begin{array}{c}\text { Fraction Pairs } \\
\text { Connected for Mutual } \\
\text { Friends }>=5(\text { F5) }\end{array}$ \\
\hline 2010 & 2011 & 0.0048997 & 0.0314609 & 0.0992321 & 0.1930776 & 0.4713363 \\
\hline 2011 & 2012 & 0.0046948 & 0.0323243 & 0.0995143 & 0.1971716 & 0.4424435 \\
\hline 2012 & 2013 & 0.0046361 & 0.0310196 & 0.0902135 & 0.1878699 & 0.4096094 \\
\hline 2013 & 2014 & 0.0045566 & 0.0303604 & 0.1019512 & 0.1827215 & 0.4180874 \\
\hline 2014 & 2015 & 0.0048533 & 0.0336583 & 0.1161154 & 0.2100379 & 0.4266714 \\
\hline 2015 & 2016 & 0.004837 & 0.0352589 & 0.1221848 & 0.2259818 & 0.425948 \\
\hline 2016 & 2017 & 0.004693 & 0.0332242 & 0.1240886 & 0.2363438 & 0.4346562 \\
\hline 2017 & 2018 & 0.004667 & 0.0364793 & 0.1229338 & 0.2430999 & 0.4427503 \\
\hline 2018 & 2019 & 0.004255 & 0.0348411 & 0.1258071 & 0.2505542 & 0.4463982 \\
\hline 2019 & 2020 & 0.0038619 & 0.0365821 & 0.1464855 & 0.2446071 & 0.4739395 \\
\hline
\end{tabular}

Analysis

From Table 3 and Table 4, it can be clearly seen that the probability of the directors forming a link in the future tends to increase with increasing the number of mutual friends between any two unrelated boards. It confirms the statement stated in the previous literature. Shahgholian, et al. (2012) and Kossinets \& Watts (2006) argued that the number of mutual affiliations increases the chances of forming a link between the boards at some point in the future [15, 16]. Figure 4 shows the graphs of empirical probability forming a new link between the directors with shared affiliations of 1, 2, 3, 4, and >= 5 from the year 2014 to 2020 in UK and EU region. As it can be observed from the two graphs, it shows an upward trend which means the chance of a pair of directors making a connection in the future increase with the increase in the number of mutual friends. However, it is noticed that in Figure 4, the probability of making a new tie of the director with sharing the same friends in UK for 2014 and 2015 are higher compared to 2016, then it starts to fall after 2016, except in 2018. While in Figure 4, the probability of forming a link between the boards in EU region in 2014 and 2015 are lower than in 2016. Then generally, from 2017 to 2020, the chance of making a link is better. 


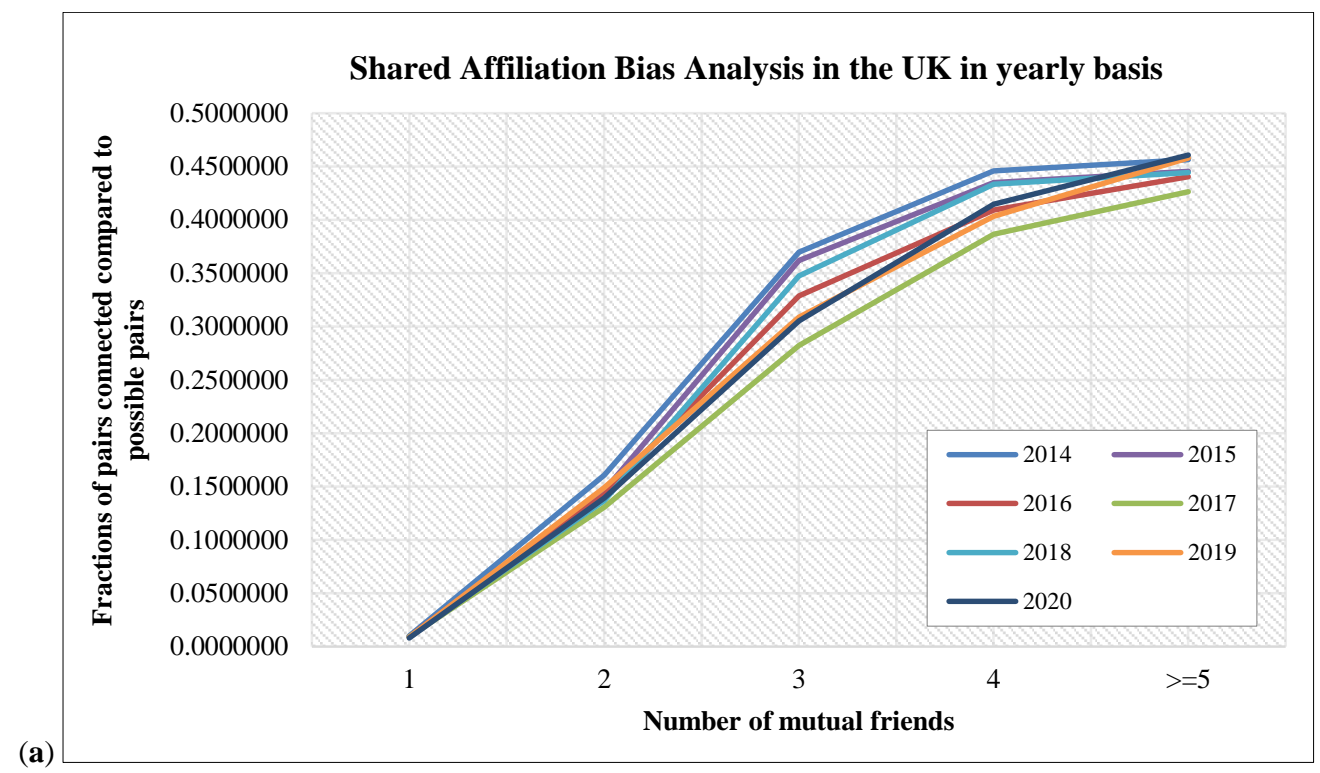

(a)

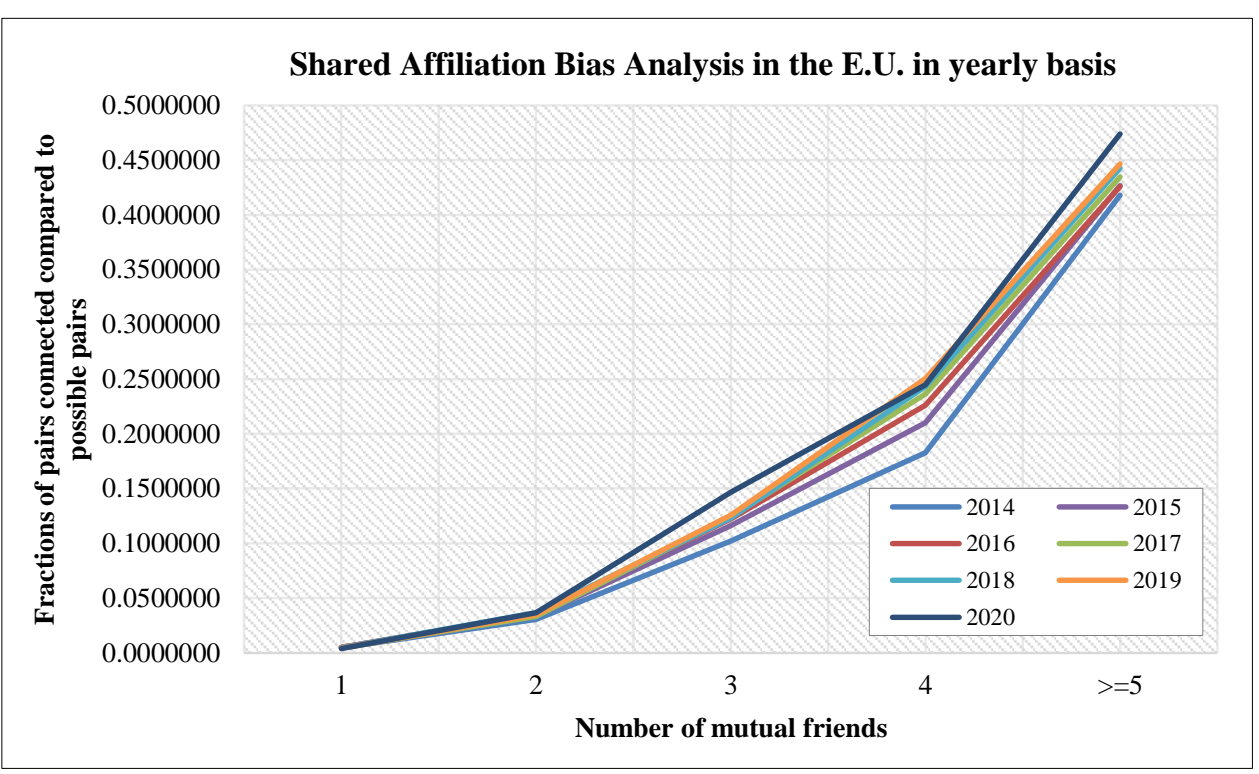

Figure 6. Comparison Analysis for Shared Affiliation Bias Analysis in yearly basis: (a) Shared Affiliation Bias Analysis in the UK; (b) Shared Affiliation Bias Analysis in the E.U.

Overall the probability of creating a new connection in EU with 1 intermediary is fluctuated throughout the year from 2011 to 2015 and reach 0.0023780 in the same year. However, it has a downward trend after 2015. As it can be observed from the Figure 4, there is a fluctuated trend of the probability of creating a new connection from 2011 to 2018 for distance of 3 for the UK and EU regions. The empirical probability is counted for 0.0002494 for UK region and 0.0001789 for EU region in 2011. For the UK region, the probability reaches the lowest point with 0.0002187 in 2013 and reaches the peak in 2018 counted for 0.0002819 . After 2018, the probability declines sharply over years. While in the EU region, it hit a high-point in 2016 with 0.0002021 and similar to the UK region, it has started to fall after 2018.

\section{4-3-Interpretation of Cyclic Closure and Shared Affiliations Bias}

The research concludes that the Brexit referendum in 2016 has a negative impact on forming a new connection of the directors in the UK since the empirical probability in the UK is declining after 2016 for the shortest path distance of lengths of 2 and after 2018 for the shortest path distance of the length of 3 . In addition, the chance of forming a link based on various mutual friends is lower in general after 2016 except in 2018. However, it is arguably that the EU region was negatively affected by the Brexit referendum. Since the graphs demonstrate a negative trend of chances of making a new link in the EU region after Brexit referendum for cyclic closure bias analysis both for the length of 2 and, while it shows a rising tendency for shared affiliations bias after 2016. 


\section{4-4-Comparison of the Number of Edges with Sector}

Also the research found that the Brexit referendum in 2016 has a negative impact on forming a new connection of the directors in the UK since the empirical probability in UK is declining after 2016 for the shortest path distance of the length of 2 and after 2018 for the shortest path distance of the length of 3 . In addition, the chance of forming a link based on various mutual friends is lower in general after 2016 except in 2018.

Result

Although only one third of the data containing sector information, the researchers grouped the data into 52 sectors with the total number of edges that found varied between 65.000 to 90.000 rows each year for the UK region while the total number of edges that found is varied between 165.000 to 244.000 rows each year for the EU region.

\section{Analysis}

As shown in Figure 5, the number of edges of banks sector hit a peak in 2013, then the number started to plateau until 2017 and dropped gradually over years while the number of edges of banks sector in the UK steadily increases from 2010 to 2019.

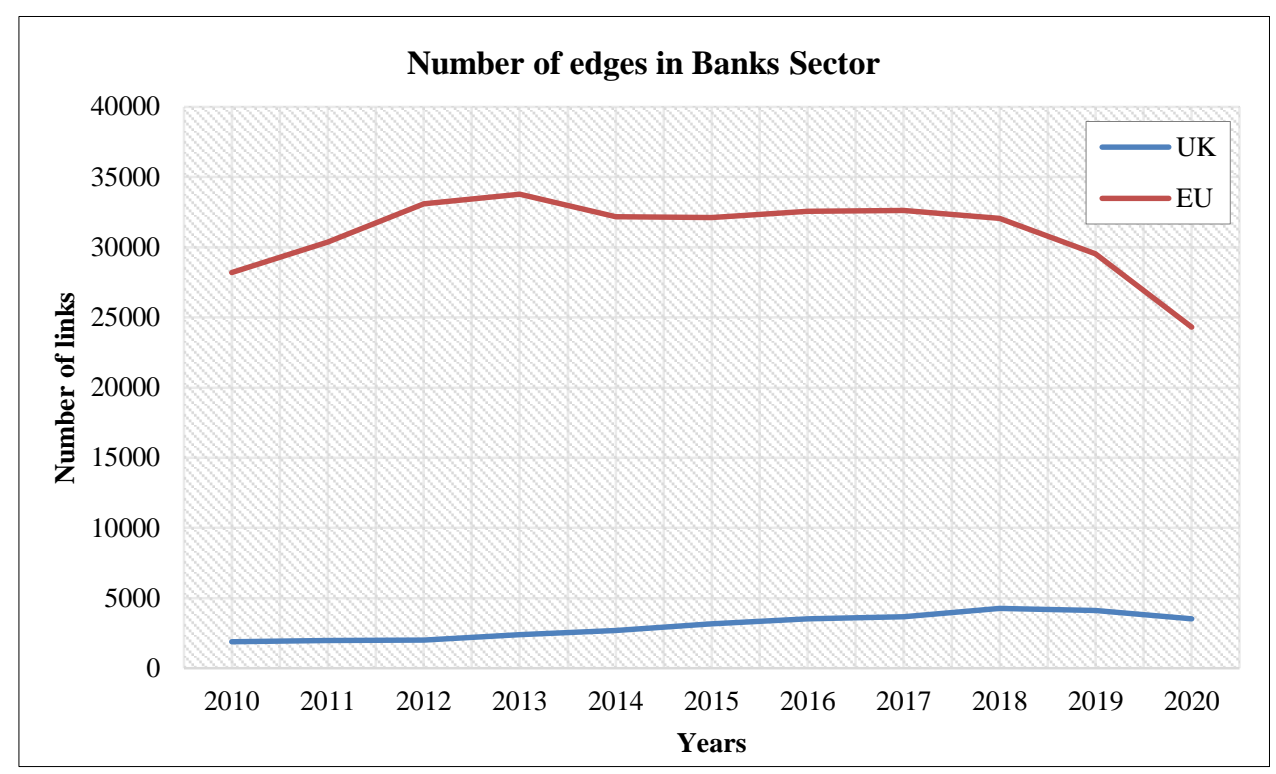

Figure 7. Comparison Analysis for the Number of Edges in the Bank Sector

As shown in Figure 6, the number of edges in UK for the consumer service sector is 290 in 2010. It started to climb and reach its highest point at 603 edges in 2017. Then it drops significantly for almost 25 percent in 2019 compared to 2017. On the other hand, it increases gradually in EU from 2010 to 2015 . Then it has slight drop in 2016 before it starts to grow sharply for about 68 percent from 2016 to 2018. Similarly, in the business service sector, the number of edges in UK increase moderately but declined after 2017 while it kept growing over the years for the EU region.

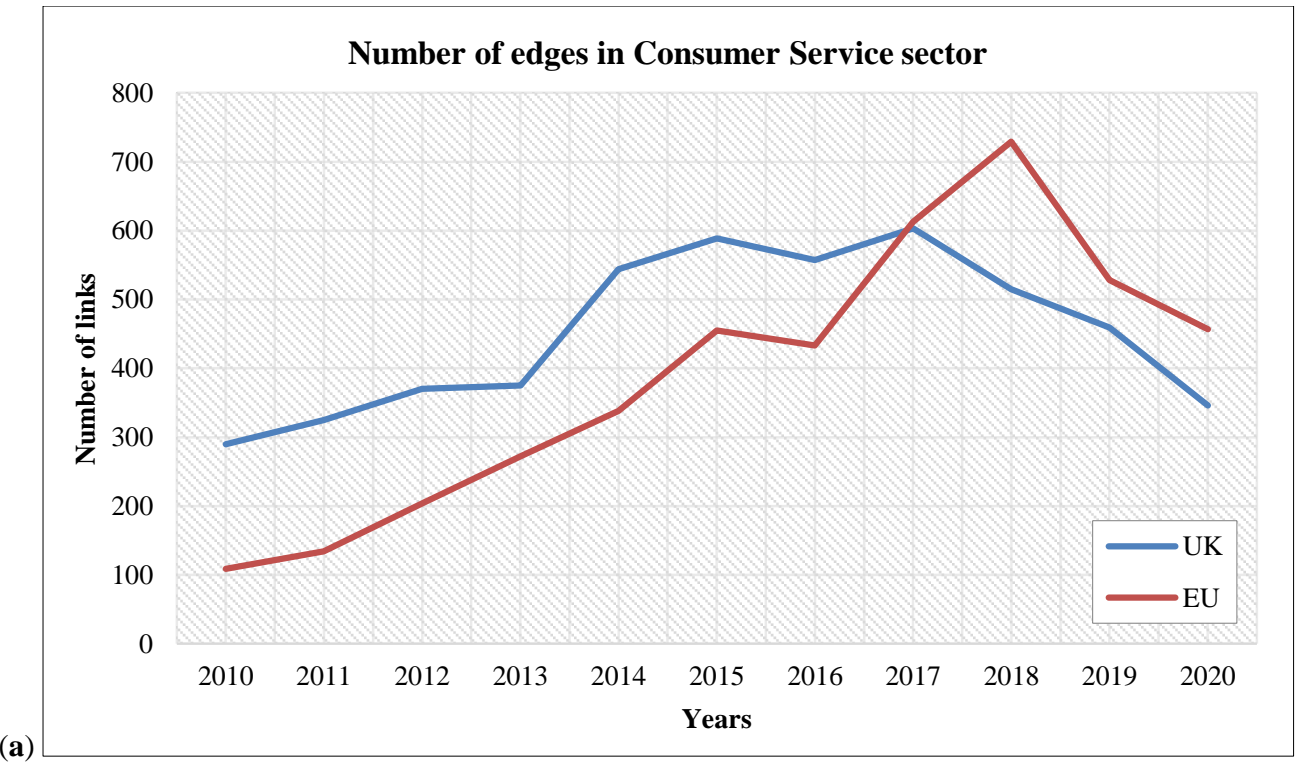




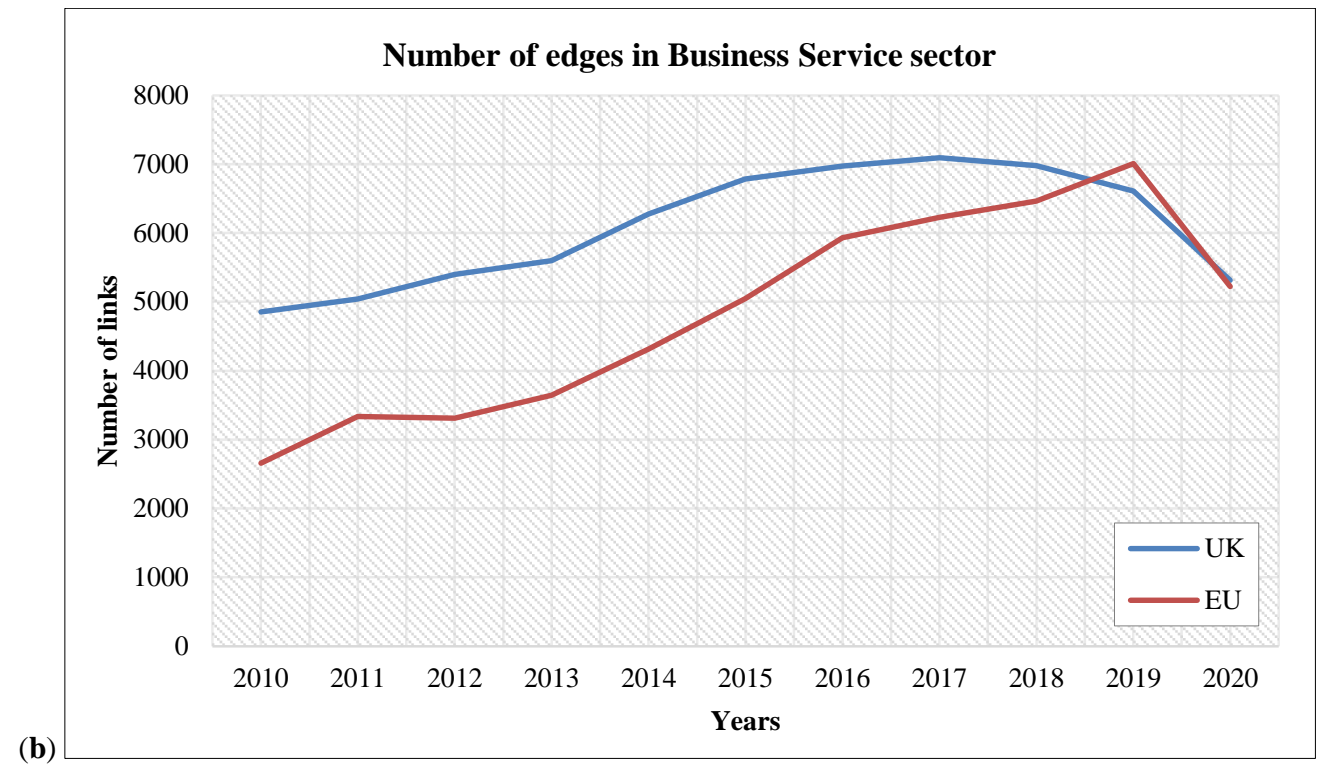

Figure 8. Comparison Analysis for the Number of Edges: (a) Analysis for the Number of Edges in the Consumer Service Sector; (b) Analysis for the Number of Edges in the Business Service Sector

In the food \& drug sector as shown in Figure 7, the number of edges In EU is increasing gradually in general. Even though it fell in 2016, the number of edges reached its highest point in 2018. On the other hand, in UK, it rises steadily to end up at 700 edges in 2015 and start to drop over the years.

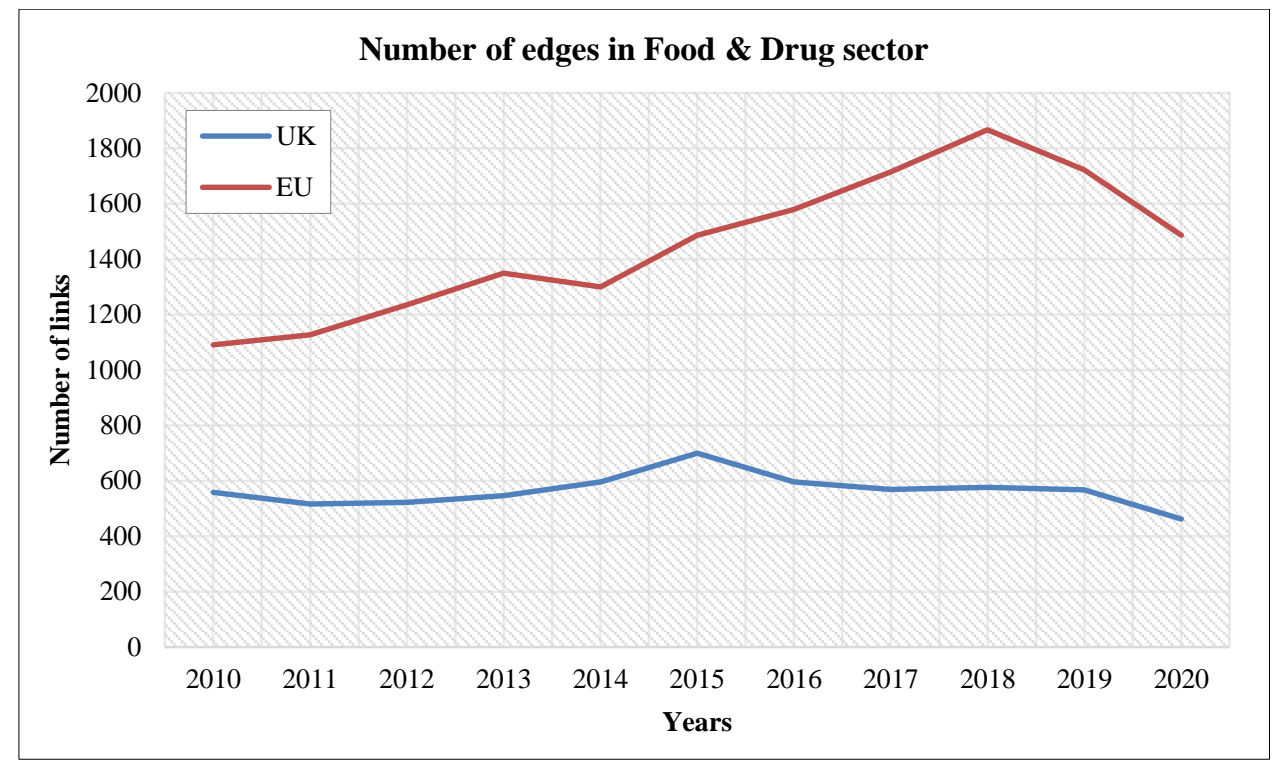

Figure 9. Comparison Analysis for the Number of Edges in Food \& Drug Sector

\section{4-5-Interpretation of the Number of Edges between Sectors}

Generally, the impact of Brexit is more obvious in the EU rather than in the UK, The consumer service sector, is the most affected by the evolution of directors' connections after Brexit. The graph indicates a sharp increasing after 2017 in EU while it shows a downward trend in the UK.

Consumer service sector is the most affected on the evolution of directors' connection after Brexit and showing a sharp positive trend after 2017 in EU while indicating a negative trend in UK Similarly, the food \& drug sector showing equal trend with consumer service sector. While bank sector displays an opposite trend compared to consumer the two previous sectors. The Brexit referendum creates a major uncertainty for the banking and financial service industry in EU [28]. For example, in Cyprus, UK-based banks borrowed an amount equal to more than 40 percent of GDP and lent to debtors in total the equivalent of over 30 percent of Cypriot GDP. 


\section{5- Conclusion}

We can accept that the Brexit referendum in 2016 has a negative impact on forming new connections between the directors in the UK since the empirical probability in the UK has declined after 2016 for the shortest path distance of length of 2 and after 2018 for the shortest path distance of length of 3 . In addition, the chance of forming a link based on varies mutual friends is lower in general after 2016 except in 2018. However, it is arguably that the EU region negatively affected by the Brexit referendum. Since the graphs demonstrate a negative trend of chances of making a new link in the EU region after the Brexit referendum for cyclic closure bias analysis both for length of 2 and, while it shows a rising tendency for shared affiliations bias after 2016. To this end, the researchers found that consumer service sector is the most affected on the evolution of directors' connections after Brexit. The graph indicates a sharp increasing after 2017 in the EU while it shows a downward trend in the UK. Next, the second most affected is food \& drug sector. It shows a steady fall after 2015 in the UK. On the other hand, the number of edges in the EU is showing a significant positive trend after 2014. Lastly, the bank sector, which has the highest number of edges in the network display an opposite trend compared to the two previous sectors. The trend of the bank sector in the UK is growing in 11 years while it shows a negative trend after 2016 in the EU.

\section{6- Declarations}

\section{6-1-Author Contributions}

Conceptualization, E. and A.F.; methodology, E.; software, E.; validation, A.F., A.S., and A.H.; formal analysis, E.; resources, A.S.; data curation, A.S.; writing — original draft preparation, E.; writing — review and editing, E., A.F., A.S., and A.H.; visualization, A.S.; supervision, A.F., A.S., and A.H.; project administration, A.F.; funding acquisition, A.H. All authors have read and agreed to the published version of the manuscript.

\section{6-2-Data Availability Statement}

Publicly available datasets were analyzed in this study. This data can be found here: [https://www.boardex.com/].

\section{6-3- Funding}

This research was partly funded by Prof. Dr. A. Nizar Hidayanto.

\section{6-4- Conflicts of Interest}

The authors declare that there is no conflict of interests regarding the publication of this manuscript. In addition, the ethical issues, including plagiarism, informed consent, misconduct, data fabrication and/or falsification, double publication and/or submission, and redundancies have been completely observed by the authors.

\section{7- References}

[1] Tetlow, G., \& Stojanovic, A. (2018). Understanding the economic impact of Brexit. Institute for government, 2-76.

[2] Dhingra, S., Ottaviano, G., Sampson, T., \& Van Reenen, J. (2016). The impact of Brexit on foreign investment in the UK. BREXIT 2016, 24(2), 1-10.

[3] Fan, Y., Stevenson, M., \& Li, F. (2020). Supplier-initiating risk management behaviour and supply-side resilience: the effects of interpersonal relationships and dependence asymmetry in buyer-supplier relationships. International Journal of Operations and Production Management, 40(7-8), 971-995. doi:10.1108/IJOPM-06-2019-0497.

[4] Mills, C. W., \& Wolfe, A. (2000). The Power Elite (Vol. 20). Oxford University Press.

[5] Palmer, D., Friedland, R., \& Singh, J. V. (1986). The Ties That Bind: Organizational and Class Bases of Stability in a Corporate Interlock Network. American Sociological Review, 51(6), 781. doi:10.2307/2095367.

[6] Withers, M., Youn (Rose) Kim, J., \& Howard, M. (2018). The evolution of the board interlock network following SarbanesOxley. Social Networks, 52, 56-67. doi:10.1016/j.socnet.2017.05.005.

[7] Davis, G. F. (1991). Agents without Principles? The Spread of the Poison Pill through the Intercorporate Network. Administrative Science Quarterly, 36(4), 583. doi:10.2307/2393275.

[8] Haunschild, P. R. (1994). How Much is That Company Worth?: Interorganizational Relationships, Uncertainty, and Acquisition Premiums. Administrative Science Quarterly, 39(3), 391. doi:10.2307/2393296.

[9] Haunschild, P. R., \& Beckman, C. M. (1998). When do interlocks matter?: Alternate sources of information and interlock influence. Administrative Science Quarterly, 43(4), 815-844. doi:10.2307/2393617.

[10] Hernandez, E., Sanders, W. G., \& Tuschke, A. (2015). Network defense: Pruning, grafting, and closing to prevent leakage of strategic knowledge to rivals. Academy of Management Journal, 58(4), 1233-1260. doi:10.5465/amj.2012.0773. 
[11] Lang, J. R., \& Lockhart, D. E. (1990). Increased Environmental Uncertainty and Changes in Board Linkage Patterns. Academy of Management Journal, 33(1), 106-128. doi:10.5465/256354.

[12] Basadur, M., Graen, G. B., \& Green, S. G. (1982). Training in creative problem solving: Effects on ideation and problem finding and solving in an industrial research organization. Organizational Behavior and Human Performance, 30(1), 41-70. doi:10.1016/0030-5073(82)90233-1.

[13] Marsden, P. V. (1990). Network Data and Measurement. In: Annual Review of Sociology, 16, 1990, S. 435-463. Annual Review of Sociology, 435-463,

[14] Farine, D. R. (2018). When to choose dynamic vs. static social network analysis. Journal of Animal Ecology, 87(1), 128-138. doi:10.1111/1365-2656.12764.

[15] Shahgholian, A., Theodoulidis, B., \& Bansal, U. (2012). Social network evolution: A case study of UK directors. Proceedings 2012 3rd International Conference on Services in Emerging Markets, ICSEM 2012, 107-114. doi:10.1109/ICSEM.2012.22.

[16] Kossinets, G., \& Watts, D. J. (2006). Empirical analysis of an evolving social network. Science, 311(5757), 88-90. doi:10.1126/science.1116869.

[17] Bloom, N., Bunn, P., Chen, S., Mizen, P., Smietanka, P., \& Thwaites, G. (2019). The Impact of Brexit on UK Firms. doi:10.3386/w26218.

[18] Kee, H. L., \& Nicita, A. (2017). Short-Term Impact of Brexit on the United Kingdom's Export of Goods. Short-Term Impact of Brexit on the United Kingdom's Export of Goods. doi:10.1596/1813-9450-8195.

[19] Ramiah, V., Pham, H. N. A., \& Moosa, I. (2017). The sectoral effects of Brexit on the British economy: early evidence from the reaction of the stock market. Applied Economics, 49(26), 2508-2514. doi:10.1080/00036846.2016.1240352.

[20] Davis, G. F., Yoo, M., \& Baker, W. E. (2003). The Small World of the American Corporate Elite, 1982-2001. Strategic Organization, 1(3), 301-326. doi:10.1177/14761270030013002.

[21] Martin, G., Gözübüyük, R., \& Becerra, M. (2015). Interlocks and firm performance: The role of uncertainty in the directorate interlock-performance relationship. Strategic Management Journal, 36(2), 235-253. doi:10.1002/smj.2216.

[22] G. S. Becker, (2009). Human capital: A theoretical and empirical analysis, with special reference to education. University of Chicago Press.

[23] Hillman, A. J. (2005). Politicians on the board of directors: Do connections affect the bottom line? Journal of Management, 31(3), 464-481. doi:10.1177/0149206304272187.

[24] Pfeffer, J., \& Salancik, G. R. (2003). The external control of organizations: A resource dependence perspective. Stanford University Press.

[25] Coleman, J. S. (2009). Social capital in the creation of human capital. Knowledge and Social Capital, 94, 17-42. doi:10.1086/228943.

[26] Lin, N. (1999). Social networks and status attainment. Annual Review of Sociology, 25(1), 467-487. doi:10.1146/annurev.soc.25.1.467.

[27] Mizruchi, M. S. (1996). What do interlocks do? An Analysis, Critique, and Assessment of Research on Interlocking Directorates. Annual Review of Sociology, 22(1), 271-298. doi:10.1146/annurev.soc.22.1.271.

[28] Deloitte. "Leaving the E.U.: What will it mean for banking and the financial services industry?" Available online: https://www2.deloitte.com/content/dam/Deloitte/cy/Documents/financial-services/CY_FinancialServices_Brexit_Noexp.pdf (accessed on August 2020).

[29] Persico, V., Pescapé, A., Picariello, A., \& Sperlí, G. (2018). Benchmarking big data architectures for social networks data processing using public cloud platforms. Future Generation Computer Systems, 89, 98-109. doi:10.1016/j.future.2018.05.068.

[30] Bourigault, S., Lamprier, S., \& Gallinari, P. (2016). Representation learning for information diffusion through social networks: An embedded cascade model. WSDM 2016 - Proceedings of the 9th ACM International Conference on Web Search and Data Mining, 573-582. doi:10.1145/2835776.2835817.

[31] Kim, J., \& Mohaisen, A. (2017). Distributed and reliable decision-making for cloud-enabled mobile service platforms. International Journal of Distributed Sensor Networks, 13(8), 1-9. doi:10.1177/1550147717726509.

[32] Jheng, G. Y., Chen, Y. C., \& Liang, H. M. (2021). Evolution pattern mining on dynamic social network. Journal of Supercomputing, 77(7), 6979-6991. doi:10.1007/s11227-020-03534-1.

[33] Alberti, F. G., Belfanti, F., \& Giusti, J. D. (2021). Knowledge exchange and innovation in clusters: a dynamic social network analysis. Industry and Innovation, 28(7), 880-901. doi:10.1080/13662716.2021.1904840. 
[34] Song, H. J., Lee, S., \& Kang, K. H. (2021). The influence of board interlocks on firm performance: In the context of geographic diversification in the restaurant industry. Tourism Management, 83, 104238. doi:10.1016/j.tourman.2020.104238.

[35] Lu, J., Yu, D., Mahmoudian, F., Nazari, J. A., \& Herremans, I. M. (2021). Board interlocks and greenhouse gas emissions. Business Strategy and the Environment, 30(1), 92-108. doi:10.1002/bse.2611.

[36] Li, M. (2021). Exploring novel technologies through board interlocks: Spillover vs. broad exploration. Research Policy, 50(9), 104337. doi:10.1016/j.respol.2021.104337.

[37] Valeeva, D., Heemskerk, E. M., \& Takes, F. W. (2020). The duality of firms and directors in board interlock networks: A relational event modeling approach. Social Networks, 62, 68-79. doi:10.1016/j.socnet.2020.02.009.

[38] Zona, F., Gomez-Mejia, L. R., \& Withers, M. C. (2018). Board Interlocks and Firm Performance: Toward a Combined AgencyResource Dependence Perspective. Journal of Management, 44(2), 589-618. doi:10.1177/0149206315579512.

[39] Kurt, Y., \& Kurt, M. (2020). Social network analysis in international business research: An assessment of the current state of play and future research directions. International Business Review, 29(2), 101633. doi:10.1016/j.ibusrev.2019.101633. 